\title{
Potato Production and Breeding in China
}

\author{
S. H. Jansky • L. P. Jin • K. Y. Xie • C. H. Xie • \\ D. M. Spooner
}

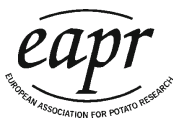

Received: 27 February 2008 / Accepted: 22 December 2008 /

Published online: 10 February 2009

(C) EAPR 2009

\begin{abstract}
China is the world's leading producer of potatoes, growing $22 \%$ of all potatoes. Production continues to rise, owing to increases in both land devoted to potato production and yield per hectare. Most potato production occurs in the northern and southwest regions of the country. The processing of coarse starch is the most important component of the potato processing industry in China, but other processing industries, such as crisps and French fries, are expanding. Major production constraints include inadequate germplasm resources for cultivar development, the lack of high quality seed potatoes, and limited access to equipment for mechanized cultivation, planting, fertilizing, spraying, and harvesting. Additional weaknesses in storage and transportation technologies must be addressed, as they are the major constraints for the healthy development of the potato industry. The introduction and improvement of these technologies will ensure the sustainable development of the potato industry in China.
\end{abstract}

Keywords Cultivar· Processing

S. H. Jansky $(\bowtie) \cdot$ D. M. Spooner

USDA-ARS, Department of Horticulture, 1575 Linden Drive, Madison, WI 53706, USA

e-mail: shelley.jansky@ars.usda.gov

L. P. Jin

Institute of Vegetables and Flowers, Chinese Academy of Agricultural Sciences, Beijing 100081, China

K. Y. Xie

CIP Beijing Liaison Office, c/o Chinese Academy of Agricultural Sciences, Beijing 100081, China

C. H. Xie

Huazhong Agricultural University, Wuhan, 430070, China 


\section{Potato Production}

For the past three decades, the economy of China has grown tremendously owing to a liberalization of the economy and an increase in international trade. Since 1993, China has been the world's leading potato producer (Wang and Zhang 2004). It currently grows $22 \%$ of the world's potato crop (Fig. 1) on $26 \%$ of the world's potato production land (Fig. 2). China contains 122 million ha of arable land, of which 4.9 million ha was used for potato production in 2006 (http://faostat.fao.org/). It produced 70 million $\mathrm{Mg}$ of potatoes in 2006, with an average yield of $14.3 \mathrm{Mg} \mathrm{ha}^{-1}$. However, for several reasons outlined below, the average yield in China varies remarkably from region to region, so the yield ranges from 33 to $4 \mathrm{Mg} \mathrm{ha}^{-1}$. In China, potato is considered to be the fourth most important food crop after rice, wheat, and maize. Since 1990, potato planting area, yield, and total production have increased (Fig. 3). In 2006, the total production, yield, and planting area were 2.20, 1.27, and 1.73 times greater than in 1990, respectively. Production doubled in 10 years, from 1990 to 2000, and continues to rise, owing to increases in both land devoted to potato production and yield per hectare. In recent years, China has become an importer of processed potatoes and an exporter of fresh potatoes (Wang and Zhang 2004).

The proportion of China's arable land devoted to potato production is expected to continue to increase for several reasons. First, in recent years potatoes have often been more profitable than other crops, such as grain crops, beans, oil crops, and cotton. It is not unusual for a potato crop to generate twice the income of other standard crops. Second, the potato processing industry is growing in China and demanding more raw materials. Finally, there is an increasing trend toward the planting of potatoes in winter fallow rice paddy fields in southern China (Qu et al. 2005). Yield is also expected to continue to increase as seed potato quality improves, cultivation technologies advance, and superior new cultivars are developed and adopted.

China covers a large geographic area, spanning latitudes from $18^{\circ} \mathrm{N}$ to $51^{\circ} \mathrm{N}$, with potatoes produced throughout the country. Potatoes are distributed in four agroecological zones (Fig. 4). Most (approximately 85\%) potato production occurs in the north single cropping zone (zone I) and the southwest mixed cropping zone (zone IV). Zone III and the southern portion of zone II are characterized by high

Fig. 1 Total production of potatoes by country in 2006 (http:// faostat.fao.org/)
Production (percent of total) World total $(2006)=315,100,319 \mathrm{Mg}$

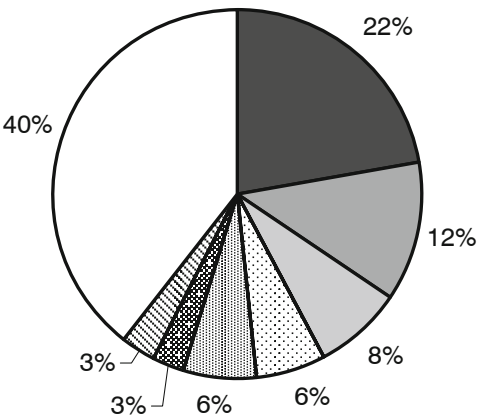

口China

口Russian Federation

口India

DUkraine

国United States

因Poland

QGermany

口Others 
Fig. 2 Land area of potatoes harvested by country in 2006 (http://faostat.fao.org/)
Area harvested (percent of total)

World total $(2006)=18,830,238$ ha

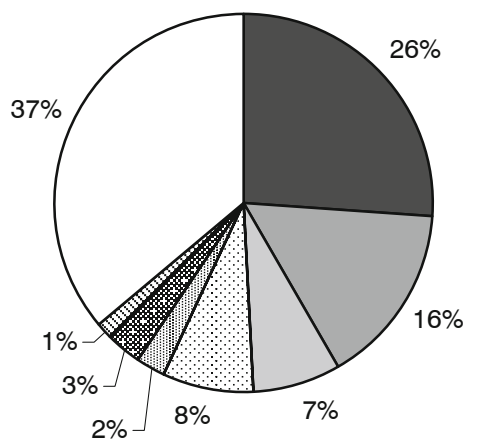

$\square$ China

$\square$ Russian Federation

$\square$ India

QUkraine

国United States

m Poland

\&Germany

口Others

rainfall, while zone I is relatively dry (Anonymous 1989). In addition, while elevations in zones II and III are low, zone IV is mountainous, except in the east.

The largest area of potato production is zone I, with favourable growth conditions such as cool temperatures, adequate sunlight, and a large differential between day and night temperatures (Anonymous 1989). The production year in zone I is similar to that of summer production regions in North America and Europe, with the crop planted in April/May and harvested in September/October. Production in this area is split between small farmers growing a subsistence crop and corporate agriculture supporting an expanding processing industry. Rotation crops include wheat, millet,

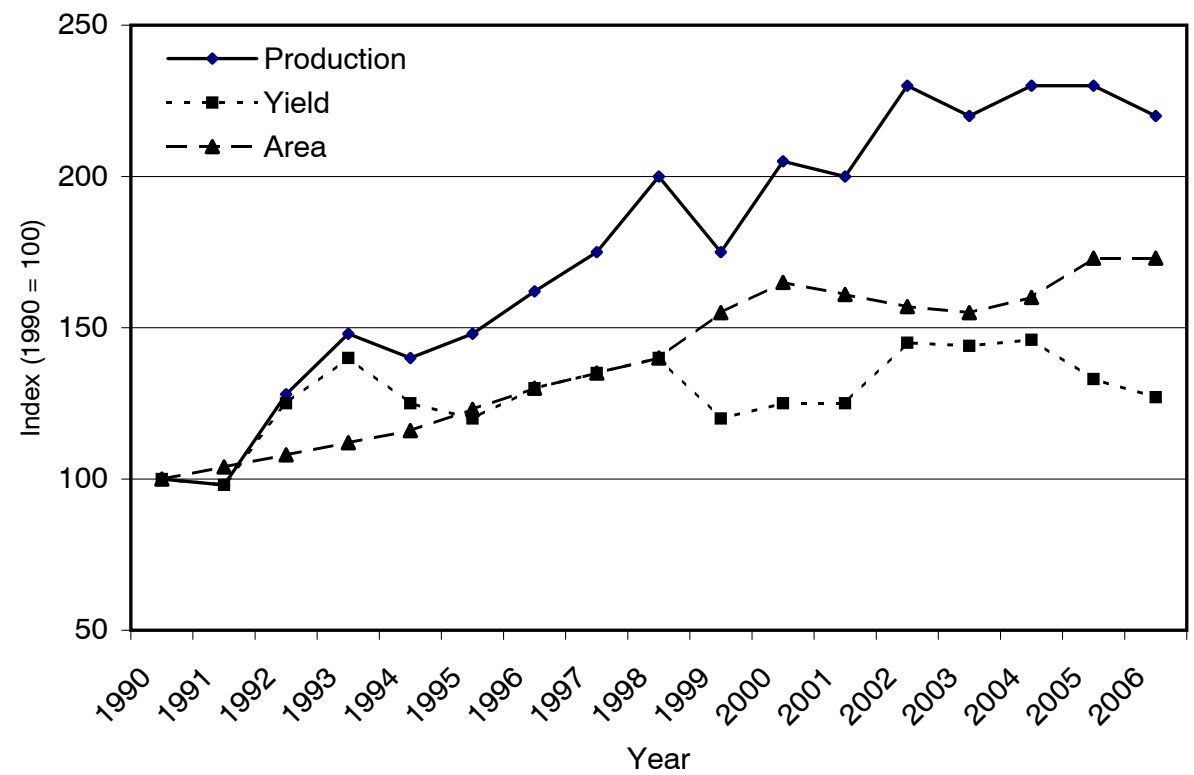

Fig. 3 Trends in total potato production, yield, and production area in China since 1990 (http://faostat.fao. org/site/567/DesktopDefault.aspx?PageID=567\#ancor) 


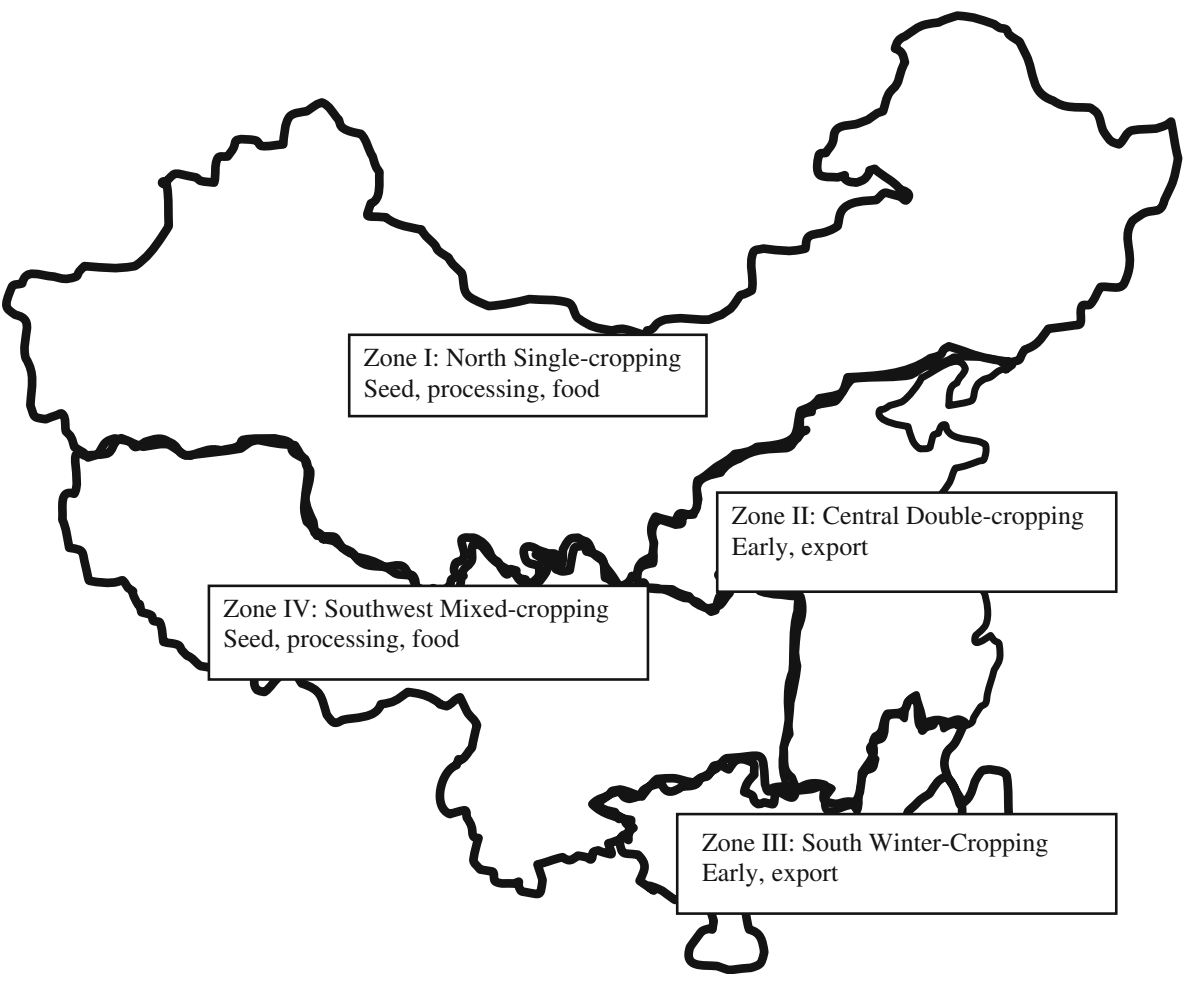

Fig. 4 Types of potato production in the four major agroecological zones in China

flax, soybeans, oats, and corn. The most significant disease problem is late blight, caused by Phytophthora infestans (Tang et al. 2007). Other major disease problems include blackleg (Pectobacterium spp.), viruses, and ring rot (Clavibacter michiganense subsp. sepedonicus). Most potato cultivars grown in this region are round whites and oblong yellows with medium to late maturity, and include the Chinese selections in the numbered series Kexin (Su and Lai 2007), Jinshu (Bai et al. 2007), Longshu (Wen et al. 2007), Qingshu (Zhang et al. 2006), Jizhangshu (Ma et al. 2007), and Zhongshu; CIP 24 (Achirana Inta), a clone from the International Potato Center; the American cv. Atlantic and the Canadian cv. Shepody.

In zone IV, where about $40 \%$ of China's potatoes are produced, mountains and plateaus present a complex topography and accompanying challenges. Elevated regions (above 1,200 m) are best for potato production owing to cool summers and abundant rainfall. In southwest China, potatoes are planted in November to February and harvested in July to September in Chongqing, west Hubei and Hunan, and part of Sichuan. In more southern regions such as Yunnan, Guizhou, and the south part of Sichuan, potatoes are planted from January to April. Common rotation crops include corn, wheat, soybeans, and sweet potato. However, in many areas, potatoes are grown intensively on what little cropland is available and rotations are limited or non-existent. The most important disease is late blight because cloud cover and frequent mists favour its development. Other significant diseases and pests include potato tuber moth (Phthorimaea operculella), bacterial wilt (Ralstonia solanacearum), and viruses. 


\section{Potato Utilization}

Most (45\%) of China's potato crop is used for table stock, while $14 \%$ is used for export and feed, and $21 \%$ is used for the production of starch and other processed products ( $\mathrm{Li}$ et al. 2004). Approximately $10 \%$ of the production is used for seed, while losses account for the remaining 10\%. Since 1990, annual per capita potato consumption in China has increased from 14.7 to $40.9 \mathrm{~kg}$. Processed potatoes have contributed little to this dramatic increase in consumption because they are so new to the consumer picture in China.

Traditionally, potato processing in China has focused on starch and noodle production. However, economic growth has resulted in a large and expanding middle class, especially in urban areas. As a result of income growth, Chinese people now have more choices about what and where to eat. They are eating out of the home more than in the past and, at home, they are demanding more convenient and unique processed potato products. Consequently, there is an increasing demand for processed products common in western societies, such as French fries and other frozen products, crisps, and dehydrated potatoes.

\section{Production Constraints}

\section{Seed Potato Production}

The lack of high-quality seed potatoes is probably the most significant constraint to the development of the potato industry in China (Kang 2007). It is estimated that only $20 \%$ of the total production area of China is planted from quality virus-free seed. The north single cropping region (zone 1) is the main seed potato production region in China, but the southwest mixed cropping region (zone IV) has also begun to produce potato seed. Southwest China is a mountainous area. A cool climate and strong winds in high altitudes prevent the growth of many other solanaceous crops and the immigration of aphids into these regions. Because of its desirable seed production conditions, this region produces almost $40 \%$ of China's seed potatoes. The seed potato industry lacks the authority to organize, manage, and coordinate efforts across broad and diverse production systems. Potato seed tubers are now produced and sold by a broad array of entities, including research institutes, universities, seed companies, private companies, and even small farmers. There is no system in place for potato seed quality monitoring and supervision. Potato seed quality varies greatly and there is no coordination between the seed potato and commercial potato industries. There are no mechanisms to separate seed from nonseed tubers, and seed crops are often not physically isolated from non-seed crops. The technology for prebasic seed (minituber) production using tissue culture is well developed in China; however, current minituber production capacity can not meet the demand for seed.

Many potato farmers use their own harvested potatoes as seed for the next season. They are not convinced of the value of buying certified seed. This results in the perpetuation and spread of viral and bacterial diseases, resulting in lower yields in successive generations. In addition, farmers minimize the cost of seed by cutting 
tubers into pieces each with a single eye. Occasionally, farmers will buy seed to counteract the inevitable decline that results from asexual propagation. However, there is no system to guarantee that the new seed is disease-free.

\section{Cultivar Development}

Potato breeding in China is a relatively new venture. It did not begin in earnest until the 1940s, when foreign cultivars were introduced. These clones were intercrossed and selfed to produce segregating populations for selection. The introduction of new germplasm has been limited, so the genetic background of Chinese potato cultivars is very narrow (Anonymous 1989; Hong et al. 2006). In a study of the genetic diversity of Chinese cultivars, 93 cultivars released before 1983 were shown to have a narrow genetic background due to common parentage (Min and Jin 2008). Even the parents of newly released potato cultivars are typically clones introduced from Europe and North America in the 1950s and 1960s. Many of these cultivars are closely related to each other, so genetic variation among their progeny is low. Germplasm resources, such as wild species and primitive cultivars, are limited and progress in the utilization of these resources has been slow. Although potato germplasm has been introduced from other countries and the International Potato Center, systematic studies on potato germplasm improvement and the use of wild potato germplasm have not been conducted owing to a lack of long-term objectives by breeding programmes.

The objectives of potato breeding programmes in China have historically focused on high yield and disease resistance in table stock clones. Consequently, most cultivars are medium to late in vine maturity and do not have acceptable processing attributes. The development of processing cultivars has only recently become a priority (Xu et al. 2006). There is a need for early cultivars in the northern and highaltitude regions, and in the southern double cropping and winter cropping regions. There is also a growing need for processing cultivars to supply the increasing demand for production of crisps and French fries. Chinese cultivars supply most of the fresh market; however, North American cultivars currently dominate the processing acreage. Shepody and Kennebec are the major cultivars used for production of French fries, while cultivars for crisp production include Atlantic and Snowden. The starch industry typically uses culls of cultivars grown for other uses owing to a lack of cultivars specifically for starch manufacture. However, efforts have been initiated to identify germplasm with starch content to provide raw materials for this industry (Liu 2006).

Disease pressure is often severe in potato fields in China, especially since the use of fungicides is limited or non-existent in most production areas. Susceptibility to these diseases reduces yield stability and production potential. Consequently, there is a need to develop cultivars with disease resistance traits. Major diseases include late blight, Potato virus Y, Potato leafroll virus, bacterial wilt, common scab (Streptomyces scabies), and bacterial ring rot (Clavibacter michiganense subsp. sepedonicus).

A set of about 30 national and provincial research institutions carry out nearly all potato breeding efforts in China. There are currently no private breeding companies. The major potato breeding programmes are at the Institute of 
Vegetables and Flowers at the Chinese Academy of Agricultural Sciences, the Keshan Agricultural Research Institute at the Heilongjiang Academy of Agricultural Sciences, the Institutes of Cash Crops at the Yunnan Provincial Academy of Agricultural Sciences, the Potato Research Institute at the Gansu Provincial Academy of Agricultural Sciences, and the Southern Potato Research Center in Enshi of Hubei Province. The efficiency of these breeding programmes could be improved by increasing the number of crosses made and the size of progeny populations, as well as by broadening the genetic base of parental material. It is interesting to note that most breeding programmes sell microtubers (virus-free tubers produced from tissue culture plantlets), seed tubers, or commercial tubers to supplement their budgets. The Ministry of Agriculture is planning to reorganize the potato research programmes in China to reduce overlap and duplication. It intends to develop a national potato research centre, along with regional centres and experimental stations based on potato production regions.

\section{Commercial Potato Production}

Most small-scale farmers use animal-drawn implements or small tractors for planting and cultivation, and then harvest the potato crop by hand. On these subsistence farms, irrigation is generally not an option, fertilizer applications are rare, and pesticides are not used. The few larger consolidated farms that exist rely on conventional farm equipment for mechanized cultivation, planting, fertilizing, spraying, and harvesting.

Most potatoes are harvested at a similar time of the year, especially in the north single cropping region. Owing to a lack of storage facilities and limited transportation options, the midseason and off-season potato supply is typically low. Because the marketing of potatoes is not distributed throughout the year, farmers sometimes find it difficult to sell their crop at harvest.

With the expansion and diversification of the potato processing industry, the requirements of raw materials will become stricter. The conventional production system, in which each individual family produces a crop on less than 1 ha, will not serve the needs of the industry. In the north single cropping region, consolidated farms with up to 100 ha of potato fields are becoming more common. Consequently, there is a growing need for improvements in all aspects of production and mechanization, including planting, nutrient management, disease control, weed control, and harvesting.

In China, the potato has historically been considered to be a low-value crop, so it has been planted in dryland conditions with low water availability and poor fertility conditions. Most of the production area is in northwest and west China, where potatoes are grown in non-irrigated fields with 200-400 mm annual rainfall and the soil is saline-salty. On large farms, irrigation is used to supplement natural rainfall. However, groundwater resources are being depleted and wells are being dug deeper to obtain water. This constraint may be the most serious limit to potato production in Inner Mongolia and Hebei. Rainfall is more plentiful in the south, where the rainy season can last up to 7 months and annual rainfall in potato production regions is typically $1,200-1,800 \mathrm{~mm}$. 


\section{Potato Processing}

The processing of coarse starch is currently the most important component of the potato processing industry in China. The capacity to process starch is greater than that of all other processing facilities. The modern potato processing industry is still in its infancy. In 2006, estimated processing capacities included 1,000,000 Mg for refined starch, 40,000 Mg for flour, 30,000 Mg for crisps, and 55,000 Mg for French fries. Actual production in 2006 was 300,000 Mg refined starch, 35,000 Mg flour, $30,000 \mathrm{Mg}$ crisps, and 50,000 Mg French fries. Currently, the quantity and quality of raw materials do not meet the demand of the growing processing enterprise owing to the lack of superior cultivars and potato production problems. To partly make up for the difference between supply and demand, in $2006,56,000 \mathrm{Mg}$ of frozen potatoes was imported from North America, and $68,700 \mathrm{Mg}$ of refined starch was imported from Europe.

Many domestic and foreign enterprises are investing or planning to invest in the potato processing industry in China. The number of processing factories and total processing capacity is expected to grow in the near future. Consequently, it will be possible to produce more new potato products. However, because of the dietary differences between Chinese and Western cultures, processed potato products will likely be somewhat different from those in the West. Processing technologies for these new products will therefore be needed.

\section{Potato Storage and Transportation}

Potato storage facilities in China are typically cellars on individual farms or community cellars in villages. Storage facilities with controlled conditions are rare and only a few processing factories can use these storage facilities to keep their raw materials. Annual losses of 10-15\% of total production occur because of improper storage and transportation. There are currently no institutions or researchers involved in the study of potato post-harvest physiology.

The transportation infrastructure in China has improved considerably in recent years. Consequently, regions along the northern fringes, such as Inner Mongolia, Heilongjiang, Gansu, Ningxia, and northern Hebei Province have become important sources of supply for fresh market potatoes in northern and southern urban areas and seed potatoes throughout China.

\section{Conclusions}

With the development of the potato processing industry in China, new potato cultivars with specific uses are needed. There is tremendous room for improvement of seed potato quality, including more strict regulations and their enforcement by authorities. There is a need to improve technologies for mechanical cultivation, field management, and the integrated control of pests. Additional weaknesses in potato processing, storage, and transportation technologies must be addressed, as they are the major constraints for the healthy development of the potato industry. The 
introduction and improvement of these technologies will ensure the sustainable development of the potato industry in China.

\section{References}

Anonymous (1989) The cultivation of Chinese potato. China Agricultural Press, Beijing, pp 5-18

Bai XD, Du Z, Qi HY, Du PB, Fan XB, Zhang YF, Wang JX (2007) Selection of a new potato variety Jinshu no. 5 with fine quality and disease resistance. Chin Potato J 21(2):128-129

Hong DI, Chen YL, Jin LP (2006) Genetic diversity analysis of Chinese main potato cultivars by RAPD and AFLP markers. Acta Agron Sin 32(6):899-904

Kang JB (2007) Current status of potato virus-free potato seed tuber production and developmental measures in Ningxia. Chin Potato J 21(2):121-122

Li Q, Xie C, Feng Z (2004) An analysis on the comparative advantages and export competitive capability of potatoes in China. Chin Potato J 18(3):129-132

Liu XC (2006) Identification and comprehensive evaluation of high starch content germplasm resources in potato. China Vegetables Suppl $50-53$

Ma H, Yin J, Zhang XJ (2007) Breeding of a new potato variety Jizhangshu no. 8. Chin Potato J 21 (3): $192-193$

Min X, Jin L (2008) Genetic relationship and diversity of approved potato cultivars (Solanum tuberosum L.) in China. School of Chinese Academy of Agricultural Sciences, Beijing

Qu D, Xie K, Jin L, Pang W, Bian C, Duan S (2005) Development of potato industry and food security in China. Sci Agric Sin 38(2):358-362

Su XT, Lai LB (2007) Performance of potato variety Kexin no. 18 sown in winter and its high-yielding cultivation techniques. Chin Potato J 21(2):118-119

Tang XB, Yang YL, Zhan K, Qian CX, Yang YF, Luo WF (2007) Occurrence and epidemic conditions for potato late blight (caused by Phytophthora infestans). Chin Potato J 21(3):135-138

Wang Q, Zhang W (2004) China's potato industry and potential impacts on the global market. Am J Potato Res 81:101-109

Wen GH, Wang YH, Li GF (2007) A new potato variety-'Longshu no. 6'. China Vegetables 6:29-31

Xu DD, Lian YX, Lin YL, Lin QY (2006) Breeding of a new processing type potato variety Quanyin no. 1. Chin Potato J 20(2):128-129

Zhang YC, Na TC, Shi L, Sun HL, Yuan JP (2006) Selection of a new potato variety Qingshu no. 8. Chin Potato J 20(6):380-381 